\title{
THE WICKED PROBLEM OF HUMANITARIAN LOGISTICS AND DISASTER RELIEF AID
}

\begin{abstract}
Purpose: Some 40 years ago Horst Rittel and Melvin Webber published a seminal paper in which they discussed the "wicked problems" facing those who sought to develop solutions to urban planning challenges. Their work recognised that many of the decisions faced by modern management are multi-faceted, and involve a plethora of stakeholders each with a diverse view of what good might look like. The aim of this paper is to consider how the ensuing rich vein of literature relating to the management of such problems might be applied to the logistic challenges of preparing for and responding to a disaster.
\end{abstract}

Design/Methodology/Approach: This paper first examines the issues, dilemmas and decisions facing the humanitarian logistician, as a key component of the preparation and response to a disaster, and concludes that they fall firmly into the ambit of a wicked problem. The paper then reviews the literature that proposes methods for management of such problems, and applies it to the humanitarian logistics field.

Findings: The paper concludes that further research is needed to understand the ways in which the three primary approaches of employing authoritative, competitive and collaborative strategies might be best evaluated and employed. In doing so, it recognises that it is essential to engage with the broader disaster management and humanitarian logistic communities in order to help operationalise this theoretical approach.

Originality/Value: Whilst the concept of a wicked problem and the associated broad spectrum of literature has developed over a considerable period of time, this has not previously been applied to the challenge of humanitarian logistics which, it is argued, meets all the criteria to be considered as a truly wicked problem.

\section{Keywords}

Wicked problems; humanitarian logistics; authoritative strategies; competitive strategies; collaborative strategies; soft systems; disaster management

\section{Categorization}

This is a conceptual paper. 


\section{Introduction}

According to the highly respected CRED International Disaster Database, the last decade has seen a significant increase in the number of disasters affecting the world from a figure of around 220/year in the mid-1990s, to a current annual figure of some 350-400. These have an impact on over 200M people and are estimated to cost some 200Bn US\$ (Rodriguez et al, 2009). Within these figures, a number of recent disaster events such as the 2005 SE Asian tsunami, the flooding in New Orleans in the wake of Hurricane Katrina and the Pakistan earthquake (2005), Cyclone Nargis in Burma and the Sichuan earthquake in 2008, and the Haiti earthquake and Pakistan flooding (2010) have all served to reinforce the need to understand how best to deliver humanitarian aid in the aftermath of such events. Furthermore, the number, magnitude and impact of natural disasters are all showing an upward trend (Scheuren et al, 2008) not least due to the pressures of population growth and, in all probability, the impact of global warming. In addition, Coleman (2006) has shown that there has been an exponential rise of man-made disasters (explosions, chemical spills, etc), albeit the number of fatalities associated with each incident has reduced ten-fold over the period.

However, the challenges facing the humanitarian logistician are immense. In many cases the disaster unfolds with little warning - effectively zero in the case of earthquakes and, perhaps, a maximum of 72 hours for wind events (ie cyclones, hurricanes or typhoons) (Regnier, 2006). In addition, the impact of such disasters is not uniform across the globe with developing countries being affected the most (Samii, 2008; Rodriguez et al, 2009). Nor is the impact uniform within a country as often it is the poorest communities who, for example, must live on marginal land such as the low lying areas of deltaic countries such as Bangladesh (Howell, 2003). Indeed, the economists Neumayer and Plümper (2007) conclude that natural disasters have a stronger negative effect on the life expectancy of women than of men - which is emphasised all the more by the magnitude of the disaster and a (potentially lower) socioeconomic status of women.

It is unsurprising, therefore, that there has been an increase in the interest of the international academic community in the challenges of humanitarian logistics (Kovács and Spens, 2009) and the concomitant rise of from a near zero baseline in 2005 to around 10 journal special editions that have or will be published in the 20082011 timeframe. Unsurprisingly given the broad nature of the challenge, the focus of such papers reflects the expertise of the authors - thus, a number of mathematical models designed to improve the management of stock levels and the efficiency of transportation have emerged from the operations research community; whilst others have considered the applicability of existing frameworks and models taken from the "for profit" or military sectors.

What has emerged clearly stemmed both from the general understanding of the humanitarian logistic challenge that can be gleaned from newspapers and the television media as well as the increasing academic contribution is the complexity of the problem faced by the logistician. The authors contend, therefore, that the reality of the preparation for, and response to, a disaster (be it natural or man made; slow or rapid onset) can be truly described as a "wicked problem" as originally defined in the seminal work of Rittel and Webber (1973). The aim of this conceptual paper is, 
therefore, firstly to justify this assertion by discussing Rittel and Webber's criteria as they apply to the challenges facing the humanitarian logistician in a similar way that Grint (2005) framed the Iraq invasion as a wicked problem and how King (1993) applied the same ideas to nuclear weapons. The second aim is to review a number of prescriptions that have been offered for the management of wicked problems and their applicability within the humanitarian logistics space.

\section{Wicked Problems}

As indicated earlier, the concept of a wicked problem was first enunciated by Horst Rittel and Melvin Webber who were considering the challenges of urban planning and design in the early 1970s. They concluded that the existing framework for analysing and solving such problems, based as it was on the application of scientific method, or on the traditional linear method (eg the typical waterfall model specifying the problem; gathering and analyzing the data; and then formulating and implementing the solution - as exemplified in Newell and Simon, 1972) was bound to fail. In developing their argument, they laid out 10 distinguishing properties of wicked problems although various commentators have since aggregated some of these (e.g. Rayner, 2006) leaving a list of six (Conklin, 2006). For simplicity, this abbreviated version will be used to demonstrate that humanitarian logistics can clearly be considered to be a wicked problem.

\subsection{You don't understand the problem until you have developed a solution.}

In many ways, this element truly defines the essence of a wicked problem. Such problems are multi-faceted and it is only through exploration of potential "solutions" that one can develop an improved understanding of the issues that one is faced with (Houghton and Metcalfe, 2010). Furthermore, there are a plethora of individuals, groups and organisations involved in the problem and, inevitably, each will have a different perspective of its nature and, hence, what is an acceptable solution. Indeed, Rosenhead (1996) observed that many of the concepts used to structure wicked problems emerge during the problem definition phase. This reinforces earlier work such as that of Ackoff (1978) who highlighted the role of designing meaningful concepts to inquire into wicked problems. The role of framing the problem, offering meaningful interpretations and reference models, involves sense making (Weick 2001) and putting the problem into terms that key stakeholders agree on. As Metcalfe (2005) noted this is a process of offering a conjectured model of what the problem is likely to be.

In the humanitarian context, a scenario such as a rapid onset disaster (eg the aftermath of a hurricane or earthquake) sees the breakdown of many existing functions that support the level of human existence in the country concerned. For example, roads and bridges may be demolished along with additional infrastructure such as the provision of electricity, telephones or water. In addition, there will, inevitably, be casualties (including deaths, injuries and those suffering from the mental after-effects of the loss of a member of their family) as well as, potentially, other negative aspects such as a breakdown in the rule of law (leading to looting and other such criminal behaviour). Thus, each of the individuals affected by a disaster will have a different perception of the problem that is shaped by their particular circumstances. 
In addition, those responding to the disaster will also have their own individual, group or organisational perspective. Each will be a unique concept but which, importantly, they will use to structure, frame and identify the problem as they see it, and which automatically leads to potential 'solutions'. Thus, for example, the perspective of the government of the country may well differ from that of the international community as exemplified by the difficulty of the latter in obtaining access to Burma in the aftermath of Cyclone Nargis in 2008 (Logs Cluster, 2008). By the same token, the view of the many responding organisations will differ according to, for example, their mandate and whether they belong to the UN family or are independent Non-Governmental Organisations (NGOs). This is not a trivial problem as there are considerable differences in areas such as the extent to which NGOs will cooperate with military forces. To the so-called Dunantist organisations (named after Henri Dunant, the founder of the Red Cross movement) this causes considerable difficulty; whereas those NGOs with a Wilsonian perspective (reflecting the view of U.S. President Woodrow Wilson) are more comfortable with such an arrangement (Stoddard, 2003). Furthermore, the number of UN Agencies and NGOs responding to a particular disaster is not insignificant with, for example, over 400 organisations and over 5,000 members of staff being present in Indonesia in the aftermath of the 2004 tsunami (Völz, 2005), and the 900 NGOs registered by the UN as being present in Haiti in 2010.

\subsection{Wicked Problems have a 'No Stopping' Rule}

It is argued that, since a wicked problem cannot be defined, it cannot be solved. Thus, whenever one might think one has reached a solution, that is only true in relation to a single definition or set of definitions amongst the many (possibly even infinite number) that will exist. Rather, it is suggested that "...the problem-solving process ends when you run out of resources, such as time, money, or energy, not when some optimal or 'final and correct' solution emerges." (Conklin, 2006, p. 14). This means that the problem solvers reach a point where the problem's reference model is seen to be satisfactory. In this way, the problem becomes structured (Mingers and Rosenhead, 2004) to the satisfaction of key actors and stakeholders and the problem can be considered 'finished' (Eden, 1987). However, as a manager related to one of the authors, it can also be seen as the phase in which one set of problems are exchanged for another set of problems.

In the humanitarian context, the cyclical nature of disaster preparation and response has been clearly spelled out by many commentators - for example the description by Safran (2005) as shown in Figure 1.

*** Take in Figure 1 about here $* \star \star$

Thus, in the aftermath of a rapid onset disaster the immediate impact is, typically, felt for some 5 days after which the national authorities and international community will have generally managed to put together the necessary resources to rescue such people as can be rescued and to provide the initial support (in the shape of food, water and shelter) for the survivors (Tatham and Kovács, 2007). The emergency element of the transition phase (see Figure 1) will then, typically, last for around a month before it is possible to start the process or returning life to a semblance of 
normality - ie the recovery phase. Thereafter, the generic aim is "build back better", in other words the opportunity to improve the lot of those affected by the disaster will be seized and, in addition, lessons will be learned that will help ensure the impact of any subsequent disasters are lessened.

Such a process can be seen at work in the aftermath of successive major cyclones that have struck Bangladesh since the onslaught of Cyclone Bhola in 1971. This catastrophic event is estimated to have killed between 250,000 and 400,000 people - a figure that probably exceed the total deaths in the many countries affected by the 2004 SE Asia tsunami. However the casualty toll from subsequent cyclones that have followed essentially the same track (ie Gorky (1991) and Sidr (2007)) has reduced by two orders of magnitude to just over 4,000 deaths (Tatham et al, 2009). Thus, whilst Bangladesh has clearly been "building back better", it remains one of the most impoverished and densely populated countries in the world and one that ranked 196/229 in terms of its per capita Gross Domestic Product (GDP)(CIA, 2010).

\subsection{Solutions to wicked problems are not right or wrong.}

Given that a wicked problem cannot be defined, and "solutions" can only be thought of as better/worse than the current situation and/or good/not good enough, this means that, in essence, there are only better or worse interpretations (Metcalfe, 2005). The key point here is that the determination of solution quality cannot be viewed from an objective perspective, and as Conklin (2006, p. 15) observes: “...many parties are equally equipped, interested and/or entitled to judge [them] and these judgements are likely to vary widely and depend on the stakeholder's independent values and goals." The degree of subjectivity involved has been linked to complexity (Stacey, 2003) and the idea that humans create complex responses to problems they face. Indeed, in the problem structuring literature a standard assumption is that multiple interpretations are involved (see, Checkland, 2005).

As a case in point, notwithstanding the clear attraction of the "build back better" mantra, one is led to the question (that is closely aligned with the first property of wicked problem (Para 2.1, above)) - namely who decides what better look should like? Thus, for example, there is a very clear desire on the part of the UN to create a more equal world society in which females and males will have equal rights, responsibilities and opportunities (UN, 2009). However such an approach causes not inconsiderable tensions in certain communities of the world and, thereby, clearly dividing the problem along different interpretative dimensions.

\subsection{Every wicked problem is essentially unique and novel.}

It also follows from the above discussion that unlike, say, solving a mathematical equation or relying on one's understanding of the physical properties of a particular material, the dynamic social interactions that surround individuals and groups mean that even generally similar problems can actually be markedly different. For instance the predicted impact of a new bridge construction project in one city may appear to be similar to that which took place in another city, but the specific factors (such as commuter movement patterns and the geographic layout of the city) can be totally different. King's (1993) earlier example of building a nuclear reactor, or Grint's 
(2005) analysis of the invasion of Iraq highlight the uniqueness of problems and their ubiquity.

In the humanitarian context, similar events may require totally different response patterns. For example, the enormous challenges faced by Haiti in the aftermath of the January 2010 earthquake are well documented (for example on the UN OCHA Reliefweb website). In short, however, the country was devastated by a 7.1 magnitude earthquake that resulted in a loss of life of some 230,000 - a figure that was more than double that recorded in respect of any previous magnitude 7 event (Bilham, 2010). To a significant extent, this was due to the pre-existing social conditions as exemplified by the Bilham's description of the lack of appropriate construction standards:

"...the buildings had been doomed during their construction. Every possible mistake was evident: brittle steel, coarse non-angular aggregate, weak cement mixed with dirty or salty sand, and the widespread termination of steel reinforcement rods at the joints between columns and floors of buildings where earthquake stresses are highest. The death and injury ... is a consequence of many decades of unsupervised construction permitted by a government oblivious to its plate-boundary location." (Bilham, 2010, p. 878).

However, by comparison, the 8.8 magnitude earthquake in Chile (which, due to the logarithmic scale for measurement, was some 350 times more powerful that its Haiti counterpart) killed some 800 people, not least due to the development and implementation of the "highly advanced anti-seismic construction standards in Chile" (Swiss Re, 2010).

In short, even when one is (simply) dealing with inanimate variables such the power of an earthquake, there are massive challenges in attempting extrapolate from one particular historic disaster to one in the future. However, the addition of the human dimension (or, more correctly, that of many many humans) into the consideration underscores the novelty of such humanitarian disasters.

\subsection{Every solution to a wicked problem is a 'one-shot operation'.}

As pointed out by Rittel and Webber (1973), you cannot realistically conduct social experiments such as building a road in order to understand the impact of its construction. Thus, the challenge of the wicked problem is that you need to try to move in the direction of what you perceive to be the "solution", but in doing so you change the nature of the problem and, hence, the solution. To emphasise this point, the authors state (p.166): 'The planner has no right to be wrong'. This is a clever play on words that highlights how people involved in wicked problems often get just one chance to make a difference. In the above example of the road, it may result in a billion dollar exercise that, instead of reducing traffic, increases overall volumes or (for example by the action of toll charges) diverts the traffic to less suitable roads or neighbourhoods.

Self-evidently every humanitarian disaster is unique - this is true even of disasters that follow a similar pattern such as the series of cyclone that have struck Bangladesh over the last 40 years. Life has not stood still in the intervening period 
and, for example, the satellite based early warning systems provide significantly better data (and, hence, forecasts of landfall, wind strength, height of tidal surge, etc) than those available in 1970 which were mainly extrapolated from the reports made by ships unfortunate enough to be in the area at the time (Frank and Husain, 1971). Clearly, it is also totally inappropriate to attempt to conduct some form of scientific experiment in order to try to understand the impact of a disaster on, for example, the ability of individuals to survive with limited food, water and/or shelter.

\subsection{Wicked problems have no given alternative solutions.}

The final characteristic of a wicked problem is that there is no set of alternative solutions on which one might draw in choosing what is perceived to be the most appropriate. There may, for example, be no solution at all because the problem itself has been misunderstood or mis-described. On the other hand, we may be faced with a plethora of potential (and competing) solutions - but even this set may not tell the whole truth as it is entirely possible that alternatives exist that we have never even considered. This ties into the idea made popular by Newell and Simon (1972) who argued that once a problem is defined, different 'solutions' can be generated. While research has shown that key ideas can be developed to frame problems differently (Houghton and Metcalfe, 2010) and surface underlying assumptions (Mitroff and Emshoff, 1979), this process comes before the 'solution' generation. Thus, Houghton and Metcalfe (2010) argue that it is precisely this creative tension that can lead to a 'synthesis' where new concepts form, and this process can help generate systemic solutions where stakeholders' needs can be accommodated (see also Checkland, 1999).

As an example of such dilemmas, various UN agencies and NGOs have considered alternative ways of assisting countries prepare for, and respond to, disasters. Amongst the options that are promoted is the idea that such agencies should not even attempt to assist as to do so interferes with the affected country's ability to develop its own policies, processes and procedures. Thus it is argued that, rather than create and maintain an emergency response capability with these agencies and NGOs, the money would be better spent building the capacity of the country to respond to this (and other) disasters using their own resources, etc. Meanwhile others argue that, whilst this is a theoretically sound approach, in the period before the desired capability has come to fruition, the absence of external assistance will lead to the unnecessary lost of life.

\section{7 $\quad$ Summarising wicked problems}

In summarising the "attributes" of a wicked problem, a useful shorthand has been offered by Head and Alford (2008) who suggest that it is their uncertainty that make them so apparently intractable. These authors suggest that such uncertainty can be categorised as substantive, strategic and institutional. Thus, the substantive dimension relates to the gaps and conflicts in one's understanding of the knowledge base surrounding the problem which, in turn, results in the absence of a clear and/or agreed understanding of the nature of the problem itself. Indeed, in many senses, this dimension reflects the essence of a wicked problem. 
The strategic element is a reflection of the numbers individuals and organisations involved in the problem and their associated perspectives and preferences, and the inevitable difficulty associated with the achievement of a common understanding of the problem. As will be discussed later in this paper, this aspect of the problem presents a particular challenge to the humanitarian logistician in view of the plethora of organisations (and, hence, supply networks) that respond to many disasters.

Finally, the institutional aspect of the problem recognises that the actors belong to many different organisations and, hence, there is a multiplicity of decision making processes which may be uncoordinated or incompatible. This tripartite view of the attributes of wicked problems has been similarly adopted by van Bueren et al (2003), albeit they refer to cognitive uncertainty instead of substantive.

As indicated in the introduction to this paper, it is argued through the examples outlined in this section, the challenges inherent in developing and implementing the logistic preparation for, and response to, a disaster are such that they clearly meet the definition of a wicked problem and, unquestionably, demonstrate the substantive, strategic and institutional dimensions summarised above. With this in mind, the next section of this paper will review the literature relating to the response to the challenge of a wicked problem.

\section{Managing a Wicked Problem}

In their original framing of the concept of a wicked problem, Rittel and Webber (1973) used the term "tame" to represent problems that were in a different class to those described above. An alternative, but complementary, perspective is that of Grint (2005) who suggests that the two categories of problem (tame and wicked) also reflect the distinction (respectively) between management and leadership. However, perhaps the key distinction is that tame problems can be accurately described and subsequently resolved - although this does not necessarily imply the existence of a unique solution.

In discussing the challenge of converting a wicked problem to a tame one, Conklin (2006) suggests a number of alternative strategies that will be briefly described. In doing so, it is important to appreciate that Conklin rejects each of them for the reasons indicated - but an understanding of the weaknesses of such approaches provides a useful pre-cursor to the later consideration of alternative means by which such problems may be managed (as distinct from solved).

- $\quad$ Lock down the problem definition. Under this approach, a manager will select a sub-set of the problem that he/she can solve and declare that this actually represents the totality of the problem which is, thus, solvable.

- $\quad$ Assert the problem is solved. Anyone of sufficient authority in relation to the problem can assert that it is solved - and, hence, it goes away.

- Specify objective parameters by which to measure the solution's success. By choosing one's means of measurement carefully and (in)appropriately, it is easy to solve a wicked problem. 
- $\quad$ Cast the problem as 'just like' a previous problem that has been solved. In a similar way to the (mis)measurement approach above, mis-describing a problem can also lead to an easy solution.

- Give up on the problem. By ignoring the problem and hoping it will go away or be solved by someone else, from a particular individual's perspective the problem is "solved".

Given, therefore, that it is not intended that one or more of the above approaches will be adopted, how then does one cope with a wicked problem?

In answering this question it is important to recognise that, by definition, a complex problem has no singular root cause of its complexity or its wickedness and, therefore, there is no single best way of tackling it (Head and Alford, 2008). By the same token, there is a danger that any problem definition that is selected has the potential to imply a preferred solution (Rittel and Webber, 1973) and, therefore, that "all proposed methods or approaches for addressing wicked problems [are] likely to be inadequate in various degrees" (Head and Alford, 2008, p.6). With these thoughts in mind, a number of broadly similar suggestions for coping with wicked problems have been suggested. Thus, Rayner (2006a), argues that there is a spectrum of possible approaches:

- Hierarchical in which the issues are simplified (or "tamed") and then routine tools can be applied.

- Competitive in which expertise is used to control resources and the problem is managed in this way.

- Egalitarian in which the problem is opened out to more stakeholders and some form of consensus reached.

Rayner (2006) acknowledges that his thinking has been developed from the work of Roberts (2000) who suggests that there are three similar strategies that can be adopted depending on the extent of the conflict surrounding the problem. In doing so, it should be noted that she adopts a slightly different taxonomy to that of Rittel and Webber, and Conklin (amongst others). Thus, Roberts differentiates between Type I (or "simple") problems in which there is a consensus on both the definition and the solution. Type II (or "complex") problems see agreement over the definition, but not the solution, and Type III problems in which there is no agreement over either the definition or solution. A similar naming convention can be found in the problem structuring literature around the use of the phrases 'ill-defined' or 'ill-structured' problems (see Checkland, 1981).

It will be appreciated that it is the Type III problems that are more closely aligned with the generic description of a wicked problem because they emphasise the lack of shape and definition related to the problem. In this regard it is not even a problem in a rational sense; rather it is an intuitive set of problems that can be observed as a 'phenomena'. What makes it different from Type I and II is that it has no formal shape that can be used to structure (and solve) it. Weber (2003) calls this the problem of the problem. In other words, the lack of definition gives rise to the 
problem of 'framing' the problem and, using the framework offered by Roberts (2000), there are a number of strategies for handling such problems:

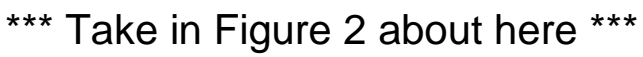

In considering how best to move forward with the Type III (or wicked) problems, Roberts argues that there are three potential strategies (authoritative, collaborative and competitive) that can be followed. Each of these will be discussed using examples from the humanitarian logistic field. However, it will be appreciated that, given the substance of the discussion so far, it is unlikely that a single strategy will be appropriate. Rather, as recommended by Rayner (2006, 2006a), the optimum approach will lie somewhere in a decision space bounded by these three approaches.

*** Take in Figure 3 about here $* \star *$

It is also useful to bear in mind the approach of Head and Alford (2008) who, reflecting the work of Heifetz (1994) in the field of leadership, argue that there are, ultimately, two dimensions to a wicked problem - that of its complexity which reflects the limited understanding of the underpinning knowledge base (including the interdependencies of processes and structures and their associated risks); and that of diversity that reflects the numbers and variety of the actors involved. Ackoff (1978) also highlighted that problems such as these are so complex that it may be better to dissolve them by looking for new concepts or ideal representations of something else. This means changing the sub systems that constitute the problem so that new interpretations dissolve the conditions that cause it to exist. This forms part of the 'idealised redesign' processes that Ackoff discussed later in his career.

\subsection{Authoritative Strategies}

As its title implies, to be successful these require the existence of an authority figure who can either impose his or her will on the remaining stakeholders or a situation in which the stakeholders agree to accept the decisions of the authority figure. In either variant, those in authority assume (or are given) the responsibility of defining the problem and the solution. Thus, a dictator can impose his or her will on the "stakeholders" or, in the case of a democracy, the stakeholders vest the power in the government and (in general) agree to abide by such decisions. In practice, the effect of both these approaches is to reduce the number of stakeholders directly involved in the decision making approach and, as a result, reduce the complexity of the problem. This overcomes the challenge of Property No 1 in the Rittel and Webber (1973) definition (see above) in that either the individual dictator, or the government as an entity, decides what the problem is and then provides a solution.

There are also obvious potential flaws in such an approach as the authority figure(s) may be wrong in their understanding of the problem and in their proposed solution. Furthermore, they may well fail to take account of Property No 6 and not look at alternative, but better, solutions.

Within the humanitarian field, the introduction of some form of mandated authoritarian approach has frequently been suggested as a means of overcoming 
the potential difficulties of coordinating the responses of the relief community as a whole. As indicated earlier the numbers of organisations (to say nothing of individuals) engaged in responding to a disaster is huge - for example, it has been estimated that there are some 30,000 internationally operating NGOs worldwide (Stoddard, 2003). Given the plethora of potentially conflicting agendas and approaches within this group of stakeholders alone, it is unlikely that an authority figure would develop on the basis of either dictat or consent.

Even the United Nations family which, although numerically smaller with around 10 agencies specifically engaged in humanitarian relief, has historically had considerable difficulty in achieving a coherent response to a disaster. This is due, in part, to internal disagreements reflecting, on the one hand, different mandates and target beneficiaries and, on the other, the desire to maximise agency funding. However, the reform programme introduced in 2005 by Jan Egeland, the then UN Under Secretary for Humanitarian Affairs, which nominated a "cluster lead" for each of 11 activities (such as logistics, emergency telecoms, water and sanitation (UN, 2009a)) can be seen as an authoritarian approach to the management of at least part of this problem. In theory, and increasingly in practice, the UN agencies are subordinating their work in the particular domain to conform with the policies laid down by the cluster lead. Indeed, in the case of logistics, the permanent presence of members of key NGOs such as Action Contre La Faim, World Vision International and Care International within the cluster HQ would indicate that this "authoritarian" approach is beginning to gain traction.

\subsection{Competitive Strategies}

Competitive strategies have an equally long pedigree and exist in many fields including those of the military and in market economies. In a market economy the wicked problem becomes about 'design' (See Coyne 2005) and gaining agreement between a higher proportion of actors (Van Bueren et al 2003) in order to devise 'competitive' strategies. These kinds of strategies are devised to competitive advantage and outwit other competitors. An example of that may be in the delivery of a strategy for taking a greater market share. The question becomes how can we know ahead of time what products are likely to sell given the constraints we currently have. This places the strategy inside the wicked problem terrain but focuses it intensely on 'competitors' instead of collaborators. If such strategies are taken to the extreme they become adversarial and can lead to violence and warfare. Also, as noted by Roberts (2000), competition can lead to the consumption of resources that could otherwise be spent on 'collaborative' problem solving. In this regard, she quotes the case of a port in the USA where a proposal for its enlargement remained mired in litigation etc for many years as the various factions fought to achieve success for their particular version of the truth. In parallel, a neighbouring port developed a multi-stakeholder consensus (ie a collaborative strategy as will be discussed below) and, as a result, was able to achieve a considerable increase in business.

Within the humanitarian logistic community, and notwithstanding the plethora of competing interests, there are relatively few instances of competitive strategies other than at what one might describe as the tactical level. Thus, for example, there may be understandable tension around the delivery of food in the aftermath of a disaster. 
By the same token, governments may attempt to coerce populations into refugee camps in specific locations in order to ease the problems of servicing this displaced population. However, at the inter-agency level, there is relatively little tension of the competitive sort. Arguably, this reflects the fact that such agencies are, in this regard, not in a zero sum game as, in terms of their output, there is a near infinite elasticity of the market. In other words there will almost always be more beneficiaries in need of support than there is the ability to provide. In that sense, therefore, there is no inter-agency competition.

On the other hand, there is unquestionably a degree of competition for funding from national, international, corporate and individual donors. This has led to the description "co-opetition" to describe the inter-NGO relationship - at one level they are cooperating in order to help each other support those affected by a disaster whilst simultaneously competing for, potentially, scarce funding. Nevertheless, even this may have its positive side as the requirement to be able to demonstrate competence to donors is leading organisations to improve their systems of governance, to develop appropriate metrics to be able to demonstrate their positive qualities, and to search for new methods and approaches that will improve their efficiency and effectiveness.

\subsection{Collaborative Strategies}

The final (and preferred) strategy suggested by Roberts (2000), and strongly supported by Verweij et al (2006) and Camillus (2008), is that of collaboration. This is based around the relatively simple premise that "the sum is greater than the total of the parts". As a proposition, it has much to offer from a theoretical perspective, but has a number of obvious disadvantages such as the "transaction costs" (attendance and meetings, the volume of communication, the difficulty of achieving agreement, etc) which increase in parallel with the size of the group that is involved. This has been ably demonstrated by Franco (2007) in his case study on using a collaborative problem structuring approach in a multi-national negotiation, whilst the roles of actors in structuring complex problems has been extensively covered in the soft operations research fields (see, for example, Mingers and Rosenhead, 2004).

In suggesting how this approach might be achieved, Roberts argues that people have to "fail into collaboration". In other words "People have to learn what does not work before they are willing to absorb what they perceive to be the extra 'costs' associated with collaboration" (Roberts, 2000, p.12). Furthermore, she considers that collaboration is a learned skill, and that it is essential for its players to have the ability to move away from a position of "I am happy to collaborate provided everyone does it my way!!".

However, it will be immediately appreciated that developing and achieving a collaborative strategy has, of itself, all of the makings of a wicked problem. Reflecting on this, both Roberts (2000) and Conklin (2006) concentrate on the essential ingredient of recognising the socially defined nature of the challenge, and that the starting positions of individuals tend to reflect their culture, education, experience, organisational drivers and experience, to name but a few influences. Thus, they argue that the first step is to achieve a shared understanding of the problem. Importantly, this does not necessarily equate to a consensus; rather to an 
understanding of where the points of agreement are. Indeed focussing on the positive aspects (ie areas of agreement) is considered to be particularly beneficial in that this leads to a strengthening of the inter-personal relationships and associated knowledge and understanding that, over time, will allow previously intractable problems to be successfully tackled.

In a similar approach that is grounded in network approaches to policy, van Beuren et al (2003, p. 196) argue that success in managing a wicked problem will reflect "the degree to which the parties succeed in reducing uncertainty through interaction and cooperation". In achieving this, they suggest that impasses (and the essential breakthroughs) typically stem from:

- Social causes such as the lack of interaction between the actors.

- Cognitive causes that reflect the different understanding of the nature, causes and effects of a problem and potential solutions.

- Institutional causes that emerge from the paucity or absence of interorganisational support mechanisms such as shared values or language.

- Network management causes that reflect the absence of strategies that help improve the levels of cooperation between actors such as the use of facilitators and mediators.

As discussed earlier, the humanitarian logistic community as a whole is massive and, in terms of the wicked problems it faces, it must interface with a plethora of interested parties that will differ from disaster to disaster and, indeed, as a given disaster unfolds. It would, therefore, be foolish to offer a prescriptive solution to the challenges it faces, not least as to do so would undoubtedly result in falling into one (or more) of the traps laid out by Conklin (2006) and listed earlier in this paper. Nevertheless, the perceived wisdom is that a collaborative strategy has much to offer and that, within this approach, the ability to achieve dialogue is key.

However, a further insight can be gained from the contribution of Head and Alford (2008) who suggest that although collaboration is of clear importance, it is particularly focussed on the diversity dimension of wicked problems. Therefore, these authors suggest that, in addition to collaborative strategies, those seeking to tame wicked problems should also address the complexity dimension through approaches that are based on (a) systems thinking and (b) adaptive leadership. The basic idea behind the suggested use of systems thinking is that it will help to broaden the search for approaches that may enable the researcher to understand the nature of the wicked problem more clearly and/or to address it more comprehensively. Through the use of a variety of systems analysis tools, it is suggested that one is better placed to understand the "tensions and contradictions" that "are most likely to be the real sources of 'wickedness' of the problem" (Head and Alford, 2008, p. 16).

In relation to the adaptive leadership approach, Head and Alford (2008) suggest that wicked problems are likely to fall outside the cognitive capacity and capability of one single leader to comprehend and address them. In doing so, they recognise the 
challenge to the traditional approach to leadership that this might well pose. Thus, rather than being led or directed, the members of the group facing the wicked problem are invited to respond to the challenge by developing and testing possible avenues to deal with the problem as part of a shared leadership and direction setting mechanism. Indeed, as noted by Mitroff and Linstone (1995) and Mitroff (2004), the role of multiple perspectives in establishing meaning in complex problems is considered to be of extreme importance. Thus, Mitroff (2004) highlights how four distinct ways of seeing, for example the 'dreamer' view, can actually create contrast and context for possible creative solutions to complex problems. It is believed that these kinds of approaches can help the goals of humanitarian logistics.

\section{Summary and Conclusion}

In the first section of this paper, the authors have argued that the challenges inherent in the logistic preparation for, and response to, a disaster fall fairly and squarely into the concept of a wicked problem as originally described by Rittel and Webber (1973). With this in mind, the second section has outlined a number of approaches to the management of such problems that have been developed within the literature and demonstrated how these might be applied to the humanitarian logistic area of operations. Self-evidently, however, there can be no prescriptive or unique solution - for if such a magic wand were to exist, the problem would cease to be wicked. It follows that each disaster will require an appropriate amalgam of the Authoritative, Competitive and Collaborative strategies that have been presented.

From this baseline it is argued that there are two important steps that can, and should, be taken to help to operationalise this conceptual approach. The first is to broaden the recognition amongst those engaged in the practice of humanitarian logistics, and especially those operating at the strategic/policy making level, that the problems are, indeed, wicked. Thus, there is no simplistic magic bullet solution even to the challenges facing one organisation, let alone the community as a whole. It is suggested that academia has a clear part to play here through the medium of teaching and education of those working in the field, through publications such as this Journal and, through briefings to umbrella bodies such as the Humanitarian Logistics Association.

In parallel with this first activity, and in recognition of the potentially enormity of the solution space (ie Figure 3), it is also argued that the three dimensions should be further explored as a matter of urgency in order to help gain a clearer understanding of their benefits and challenges, and their practical limitations. Whilst clearly academics have a significant contribution to make to such a process, what is equally clear from the early research in this field is its inherent complexity and counterintuitive complications. Thus, it is of especial importance that any investigations are developed in close concert with a broad range of practitioners - and, in particular, those with knowledge and experience of viewpoints other than the "western" perspective that has, unsurprisingly, been in the ascendancy to date.

\section{Acknowledgements}

The authors would wish to acknowledge with grateful appreciation the support of the editors of this Journal and comments of the anonymous reviewers.

\section{References}


Ackoff, R. L. (1978), The Art of Problem Solving, John Wiley, New York.

Bilham, R. (2010), "Lessons from the Haiti Earthquake", Nature, Vol. 463, February, pp. 878-9.

Coyne, R. (2005) "Wicked Problems Revisted", Design Studies, Vol 26, pp.5-17.

van Bueren, E. M., Klijn, E-H. and Koppenjan, J. F. M. (2003), "Dealing with Wicked Problems in Networks: Analyzing an Environmental Debate from a Network

Perspective," Journal of Public Administration Research and Theory, Vol. 13, No. 2, pp. 193-212.

Camillus, J. C. (2008), "Strategy as a Wicked Problem", Harvard Business Review, May, pp. 99-106.

Checkland, P. B. (1981), Systems Thinking, Systems Practice, John Wiley, UK

Checkland, P. B. (1999), Soft Systems Methodology: A 30-Year Retrospective, John Wiley, UK.

Checkland, P. B. (2005), "Webs of significance: The work of Geoffrey Vickers", Systems Research and Behavioural Science, Vol. 22, No. 4, pp. 285-290.

CIA (2010), "World Facts Book", available at:

https://www.cia.gov/library/publications/the-world-factbook/rankorder/2004rank.html (accessed 16 August 2010).

Coleman, L. (2006), "Frequency of Man-Made Disasters in the $20^{\text {th }}$ Century," Journal of Contingencies and Crisis Management, Vol 14. No. 1, pp. 3-11.

Conklin, J. (2006), Dialogue Mapping: Building Shared Understanding of Wicked Problems, John Wiley \& Sons, Chichester.

Eden, C. (1987), "Problem Solving or Problem Finishing", in, Jackson M.C. and Keys, P. (Eds), New Directions for Management Science, Gower Publishing Company, UK.

Franco, L. (2007), "Assessing the impact of problem structuring methods in multiorganizational settings: an empirical investigation", Journal of the Operational Research Society, Vol. 58, No. 6, pp.760-768.

Frank, N. L. and Husain, S. A. (1971), "The deadliest tropical cyclone in history?", Bulletin of the American Meteorological Society, Vol. 52, No. 6, pp. 438-444.

Grint, K. (2005), "Problems, problems, problems: The social construction of 'leadership' ", Human Relations, Vol. 58. No. 11, pp. 1467-1494.

Head, B. and Alford, J. (2008), "Wicked Problems: The Implications for Public Management", Panel on Public Management in Practice, International Research 
Society for Public Management, $12^{\text {th }}$ Annual Conference, 22-28 March 2008, Brisbane.

Heifetz, R. A. (1994), Leadership Without Easy Answers, Harvard Business Press, Cambridge, MA.

Houghton, L. and Metcalfe, M. (2010), "Synthesis and Conception Shifting", Journal of the Operational Research Society, Vol. 61, No. 6, pp. 953-963.

Howell, P. (2003), "Indigenous early warning indicators of cyclones: potential application in coastal Bangladesh, Benfield Hazard Research Centre, available at: www.abuhrc.org/Publications/Working\%20Paper\%206.pdf (accessed 16 August 2010).

King, J. (1993), "Learning to solve the right problems: The case of nuclear power in America", Journal of Business Ethics, Vol. 12, No. 2, pp. 105-114.

Kovács, G. and Spens, K. M. (2009), "Identifying challenges in humanitarian logistics", International Journal of Physical Distribution and Logistics Management, Vol. 39, No. 6, pp. 506-528.

Logs Cluster (2008), "Logistics Cluster Myanmar: Cyclone Nargis Emergency Response 10th May - 10th August 2008, End of Mission Report", available at: www.logcluster.org/23003/mm08a/LogsCluster MMR EndofMissionReportE 080810.pdf (accessed 16 August 2010).

Metcalfe, M. (2005), "Conjecture first problem solving", Systems Research and Behavioural Science, Vol. 22, pp. 537-546.

Mingers, J. and Rosenhead, J. (2004), "Problem structuring methods in action", European Journal of Operational Research, Vol. 152, pp. 530-534.

Mitroff, I.I. and Emshoff, J.R. 1979, "On strategic assumption making: A dialectical approach to policy and planning", The Academy of Management Review, Vol. 4, No. 1, pp.1-12.

Mitroff, I.I. and Linstone, H.A. (1995), The Unbounded Mind, Oxford University Press, USA.

Mitroff, I.I. (2004), "William James and a theory of thinking", Journal of Information Technology Theory and Application, Vol. 6, No. 2, pp. 83-90.

Neumayer, E. and Plümper, T. (2007), "The Gendered Nature of Natural Disasters: The Impact of Catastrophic Events on the Gender Gap in Life Expectancy, 19812002", Annals of the Association of American Geographers, Vol. 97, No. 3, pp. 551566.

Newell, A. and Simon H. A. (1972), Human Problem Solving, Prentice Hall, USA. 
Rayner, S. (2006), "Wicked problems: clumsy solutions", Jack Beale Memorial Lecture at the University of New South Wales, in Sydney, Australia, in July 2006, presentation text, available at:

www.sbs.ox.ac.uk/research/Documents/Steve\%20Rayner/Steve\%20Rayner,\%20Jac k\%20Beale\%20Lecture\%20Wicked\%20Problems.pdf (accessed 16 August 2010)

Rayner, S. (2006a), "Wicked problems: clumsy solutions", Jack Beale Memorial Lecture at the University of New South Wales, in Sydney, Australia, in July 2006, presentation slides, available at:

www.sci-soc.net/SciSoc/NoticeBoard/News/Wicked+problems+clumsy+solutions.htm (accessed 16 August 2010).

Regnier, E. (2006), "Doing something about the weather", Omega, Vol. 36, pp. 2238.

Rittel, H. W. J. and Webber, M. M. (1973), "Dilemmas in a General Theory of Planning", Policy Sciences, Vol. 4, pp. 155-169.

Roberts, N. (2000), "Wicked Problems and Network Approaches to Resolution.", International Public Management Review, Vol. 1, No. 1, pp.1-19.

Rodriguez, J., Vos, F., Belwo, R. and Guha-Sapir, D. (2009), "Annual Disaster Statistical Review 2008: The numbers and trends." Centre for Research on the Epidemiology of Disasters (CRED), available at:

www.cred.be/sites/default/files/ADSR_2008.pdf (accessed 16 August 2010).

Rosenhead, J. (1996), "What's the problem? An introduction to problem structuring methods", Interfaces, Vol. 26, No. 6, pp.117-131.

Safran, P. (2005), "Disaster and Emergency Policy, May 2005", Asian Development Bank, available at:

www.adb.org/Documents/Policies/Disaster Emergency/disaster emergency.pdf (accessed 16 August 2010).

Samii, R. (2008), "Leveraging Logistics Partnerships - Lessons from Humanitarian Organizations", ERIM PhD Series, Erasmus School of Economics, Holland.

Scheuren, J-M., le Polain de Waroux, O., Below, R., Guha-Sapir, D. and Ponserr, R. (2008), "Annual Disaster Statistical Review 2007: The numbers and trends", Centre for Research on the Epidemiology of Disasters (CRED), available at:

www.cred.be/sites/default/files/ADSR_2007.pdf (accessed 16 August 2010).

Stacey, R. (2003), "Learning as an activity of interdependent people", The Learning Organisation, Vol.10, No.6, pp.323-331.

Stoddard, A. (2003), "Humanitarian NGOs: challenges and trends", HPG Briefing, 12, July, available at: www.odi.org.uk/resources/download/272.pdf (accessed 16 August 2010). 
Swiss Re (2010), "Chile earthquake expected to be a major insurance event", available at: http://www.swissre.com/rethinking/ (accessed 17 May 2010).

Tatham, P. H. and Kovács, G. (2007), "The Humanitarian Supply Network in Rapid Onset Disasters", Proceedings of NOFOMA, 7/8 June, Rejavik, Iceland.

Tatham, P. H., Spens, K. and Oloruntoba, R. (2009), "Cyclones in Bangladesh - A case study of a whole country response to rapid onset disasters", Proceedings of the Production and Operations Management (POMS) Conference, Orlando,1-4 May.

UN [United Nations] (2009), "Concepts and Definitions", Office of the Special Advisor on Gender Issues and the Advancement of Women (OSAGI), At:

www.un.org/womenwatch/osagi/conceptsandefinitions.htm (accessed 16 August 2010).

UN [United Nations] (2009a), "Humanitarian Reform", available at: www.humanitarianreform.org/ (accessed 16 August 2010).

Verweij, M., Douglas, M., Ellis, R., Engel, C., Hendriks, F., Lohmann, S., Ney, S., Rayner, A. and Thompson, M. (2006), "The Case for Clumsiness", in Verweij, M. and Thompson. M. (Eds), "Clumsy Solutions for a Complex World", Palgrave Macmillan, Basingstoke, UK.

Völz, C. (2005), "Humanitarian coordination in Indonesia: an NGO viewpoint", Forced Migration Review, Special Issue, July 26-27, pp. 26-28.

Weick, K. (2001), Making Sense of the Organisation, Blackwell Business, Oxford, UK.

Weber, R. (2003), “Editor's comments: The problem of the problem”, MIS Quarterly, Vol. 27, No. 1, pp. iii-ix. 
Figure 1: The Disaster Management Cycle

(Source: Safran, 2005, p.22)

The Disaster Management Cycle

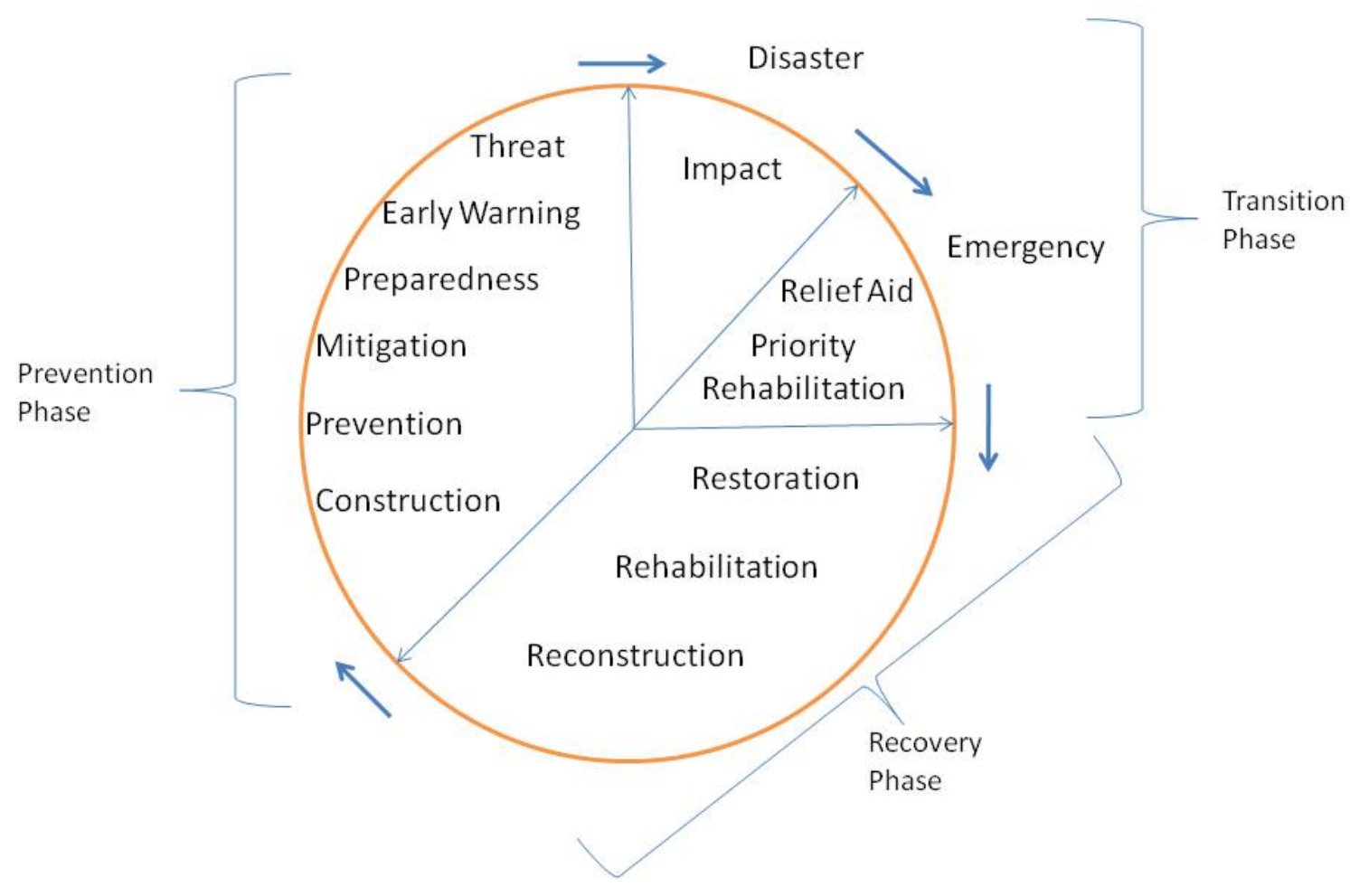


Figure 2: Coping Strategies to Deal with Wicked Problems (After Roberts, 2000, p.3)

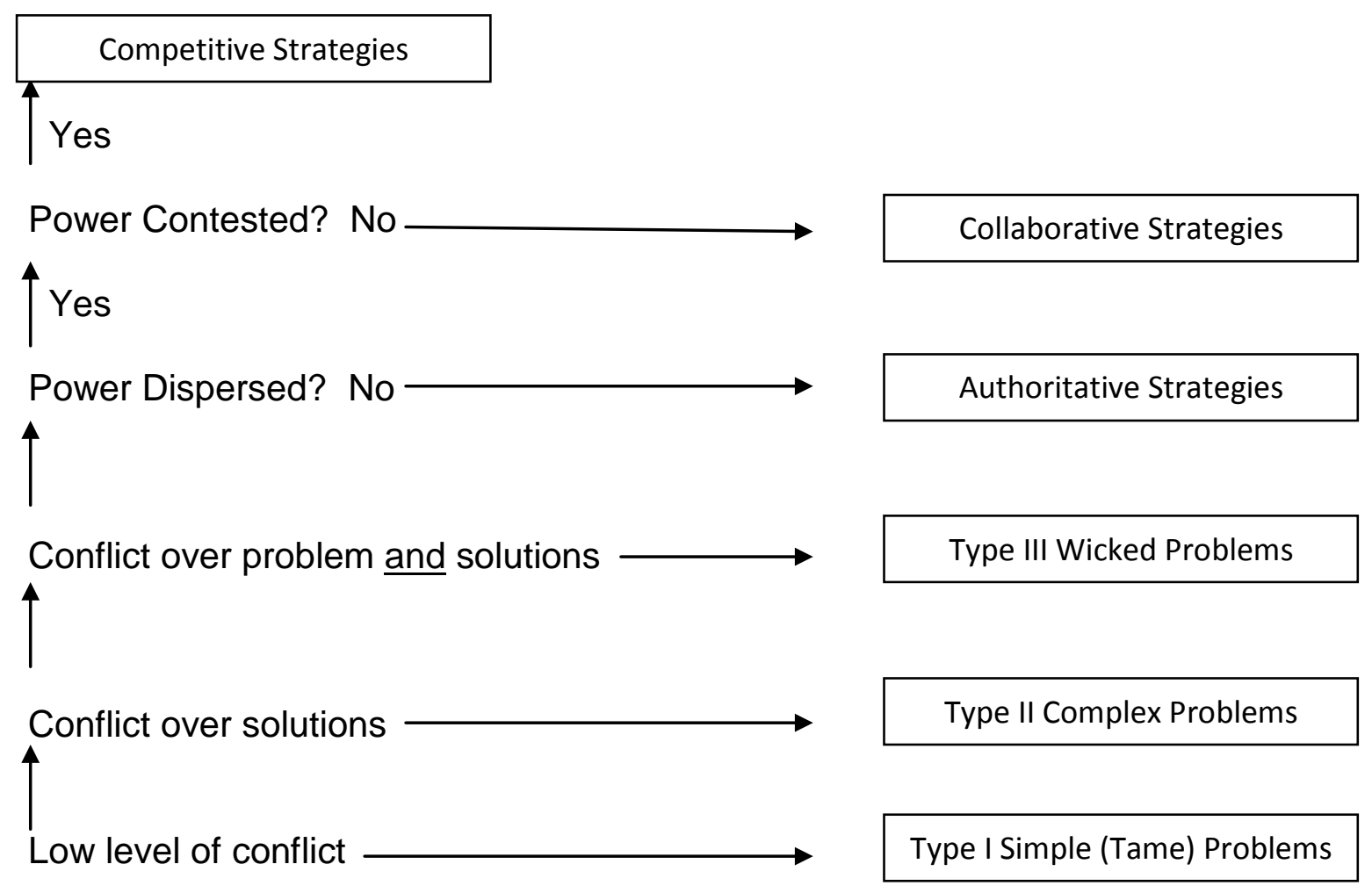


Figure 3: A Dynamic Solution Space

(Modified from Rayber, 2006a)

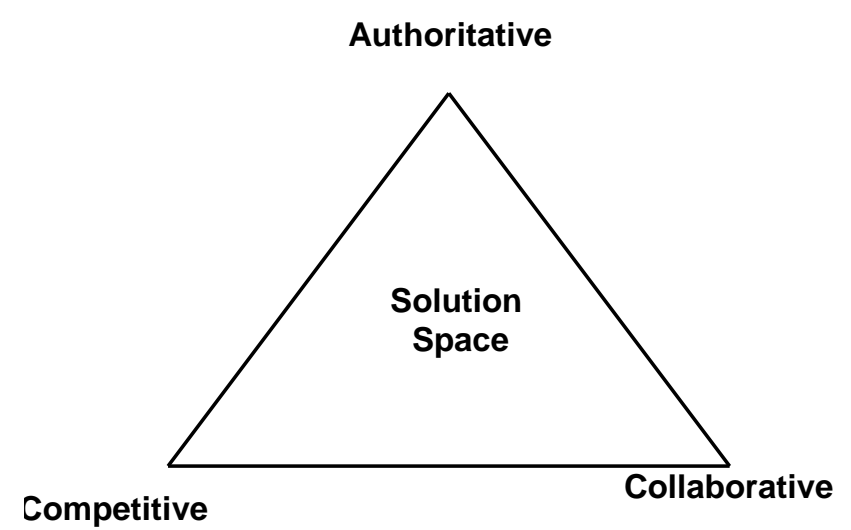

